\title{
COMPUTERIZED THREE-DIMENSIONAL PEDICLE MORPHOMETRY FROM COMPUTED TOMOGRAPHY IMAGES OF THE THORACIC SPINE
}

\author{
DEJAN KNEZ AND TOMAŽ VRTOVEC \\ University of Ljubljana, Faculty of Electrical Engineering, Tržaška cesta 25, SI-1000 Ljubljana, Slovenia \\ e-mail: dejan.knez@fe.uni-lj.si, tomaz.vrtovec@fe.uni-lj.si \\ (Received February 17, 2020; revised May 8, 2020; accepted May 16, 2020)
}

\begin{abstract}
Knowledge of pedicle morphometry is valuable for a safe and reliable pedicle screw placement. In this study, we performed and evaluated computerized pedicle morphometry measurements from preoperative computed tomography (CT) images of the thoracic spine from 26 subjects. Manual measurements of the pedicle width, height and chord length were obtained for 540 thoracic pedicles in selected cross sections of orthogonal and oblique multiplanar reconstructions (MPRs). Computerized measurements of the pedicle width, height, length, chord length, transverse angulation, sagittal angulation and cross-sectional area were obtained for the same pedicles by an automated method that is based on parametric modeling of vertebral structures in three dimensions (3D). Statistical analysis revealed that manual measurements from orthogonal MPRs were significantly different $\left(p \leq 1.1 \cdot 10^{-3}\right)$ when compared to those from oblique MPRs and computerized measurement in $3 \mathrm{D}$, with the respective mean absolute difference (MAD) \pm standard deviation (SD) of $0.77 \pm 0.56 \mathrm{~mm}$ and $0.74 \pm 0.57 \mathrm{~mm}$ for the pedicle width, and $1.31 \pm 1.08 \mathrm{~mm}$ and $1.45 \pm 1.10 \mathrm{~mm}$ for the pedicle height. No statistically significant differences $(p \geq 0.12)$ were observed between manual measurements from oblique MPRs and computerized measurements in $3 \mathrm{D}$, with MAD $\pm \mathrm{SD}$ of $0.44 \pm 0.35 \mathrm{~mm}, 0.56 \pm 0.52 \mathrm{~mm}$ and $1.72 \pm 1.29 \mathrm{~mm}$ for the pedicle width, height and chord length, respectively. The advantage of computerized measurements is that they allow the extraction of additional pedicle morphometric parameters, which are important for preoperative planning of pedicle screw placement, or can be used for population and demographic studies using larger pedicle databases.
\end{abstract}

Keywords: computer assisted preoperative planning, pedicle modeling in 3D, pedicle morphometry, pedicle screw placement planning, vertebra morphometry.

\section{INTRODUCTION}

Posterior anchorage of two or more adjacent vertebrae with pedicle screws and connecting rods is nowadays the preferred surgical treatment for several spinal deformities, such as scoliosis, kyphosis, fractures and tumors (Fuchs et al., 2016; Cordemans et al., 2017; Davis et al., 2017; Kong et al., 2017; Pusceddu et al., 2017; Wojnar et al., 2019). During surgery, pedicle screws are inserted into vertebral bodies through the corresponding pedicles and afterwards posteriorly connected with rods. Although the pedicles are, from the biomechanical aspect, the strongest part of vertebrae (Wang et al., 2016; Pishnamaz et al., 2018), they are also the narrowest part with a highly variable morphology among vertebral levels and individuals. The narrow shape of the pedicles varies among vertebral levels, especially in the thoracic spine where pedicles are narrower compared to those in the lumbar spine (Zhuang et al., 2011). Therefore, a high accuracy of pedicle screw placement is required, especially because a pedicle or vertebral body wall breakthrough can lead to serious nerve or internal organ injuries (Chan and Kwan, 2017; Davis et al., 2017; Kong et al., 2017). To prevent such injuries, preoperative planning of pedicle screw placement is essential (Knez et al., 2019), and is strongly related to the pedicle morphometry, i.e. the precise measurement of pedicle shape parameters, that helps spine surgeons to choose an appropriate surgical strategy through the corresponding screw dimensions and trajectories (Gstoettner et al., 2011; Simpson et al., 2016; Ma et al., 2016; Yang et al., 2019). Recent studies emphasized the importance of pedicle morphometry, especially in the case of scoliosis for a better understanding of its mechanism (Brink et al., 2017), where pedicles are smaller and narrower in the concave side, and therefore the selection of an appropriate pedicle screw size and insertion trajectory reduces the risk of pedicle screw breakthrough and injuries (Davis et al., 2017; Gao et al., 2017).

Pedicle morphometry has been so far evaluated manually by direct measurements with digital calipers from cadavers (Vaccaro et al., 1995; Panjabi et al., 1997; Parent et al., 2004; Lien et al., 2007; Morales-Avalos et al., 2014; Yu et al., 2014; 2015), which proved to be relatively inaccurate and not useful for preoperative pedicle screw placement planning, and by indirect measurements with dedicated 

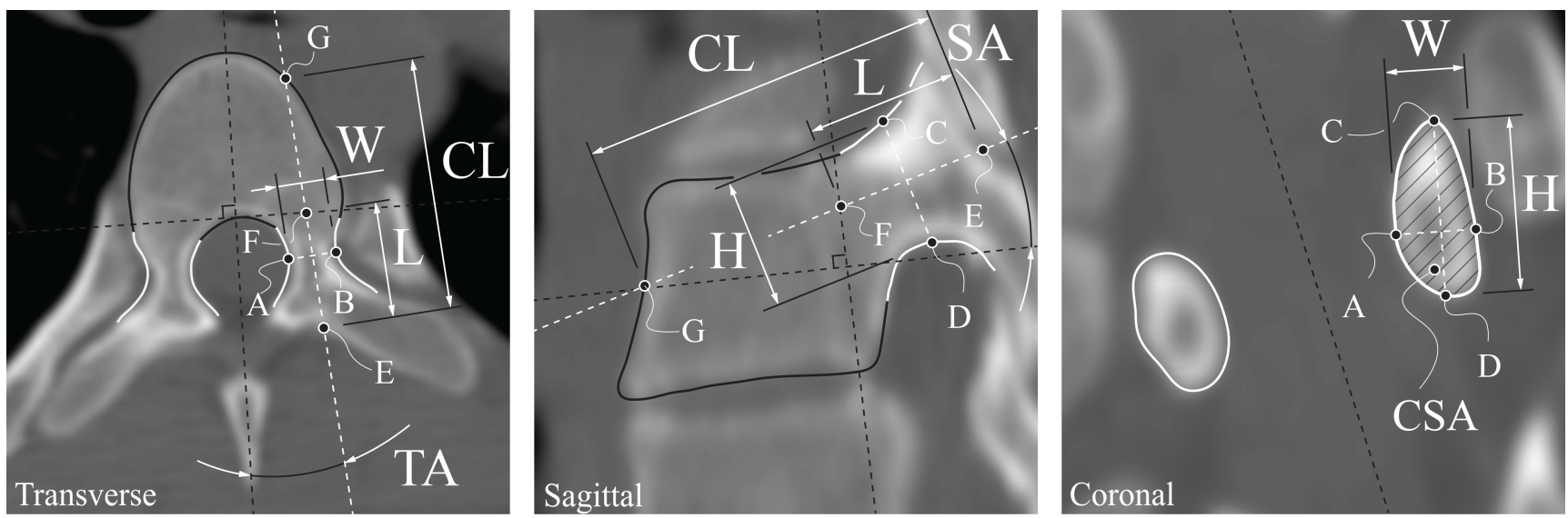

Fig. 1. Pedicle morphometric parameters, shown in orthogonal multiplanar reconstructions: width $W$ and height $H$ are, respectively, the distances from the left-most $(A)$ to the right-most point $(B)$ and from the superior-most $(C)$ to the inferior-most point $(D)$ of the pedicle in the coronal plane at the location of its isthmus; length $L$ and chord length $C L$ are the distances from the posterior cortical entry point $(E)$ to, respectively, the posterior longitudinal ligament $(F)$ and the anterior vertebral cortex $(G)$; transverse angulation TA is the angle between the left-to-right plane of vertebral body symmetry and the pedicle axis projected onto the superior-to-inferior plane of vertebral body symmetry; sagittal angulation SA is the angle between the superior-to-inferior plane of vertebral body symmetry and the pedicle axis projected onto the left-to-right plane of vertebral body symmetry; cross-sectional area CSA is the pedicle cross-section at its isthmus.

virtual tools from orthogonal or oblique multiplanar reconstructions (MPRs) in three-dimensional (3D) computed tomography (CT) or magnetic resonance (MR) images of the spine (Liljenqvist et al., 2002; Takeshita et al., 2009; Kang et al., 2011; Kretzer et al., 2011; Kuraishi et al., 2013; Sarwahi et al., 2014; Peters et al., 2015; Kaur et al., 2016; Brink et al., 2017; Mohanty et al., 2018; Brink et al., 2020). However, vertebrae may vary in position and orientation, especially in the case of spine degenerations, and therefore indirect manual measurements of pedicle morphometry cannot be uniquely and accurately obtained. On the other hand, computerized tools based on automated image processing and analysis methods have proved to be, also for various spine related measurements (Vrtovec et al., 2012; Nault et al., 2014), more accurate and reliable than manual approaches, and have been so far applied to pedicle morphometry in a limited manner, e.g. it was evaluated from CT cross-sections that were parallel to the corresponding superior vertebral endplates (Brink et al., 2017; Mohanty et al., 2018), or only a subset of morphometric parameters were measured (Brink et al., 2020). The aim of this study is to describe the concept and perform computerized measurements of a complete set pedicle morphometric parameters, and compare them against corresponding manual measurements from CT images of the thoracic spine.

\section{MATERIALS AND METHODS}

\section{CT IMAGES}

This study includes retrospectively collected images of 26 patients (males: 13; females: 13; mean age: 17.1 years; range $12-34$ years) with thoracic spinal deformities (adolescent idiopathic scoliosis: 23; Scheuermann's kyphosis: 3) that were appointed for the pedicle screw placement surgery at Orthopaedic Hospital Valdoltra, Slovenia, and therefore received a preoperative CT scan (GE LightSpeed VTC scanner; pixel size: $0.25-0.40 \mathrm{~mm}$; slice thickness: $0.6 \mathrm{~mm}$ ). Confidential image information was anonymized before further manipulation, and the use of images was approved by the Institutional Review Board.

\section{PEDICLE MORPHOMETRY}

The observed pedicle morphometric parameters are shown in Fig. 1 and are represented by the pedicle width, height, length, chord length, transverse angulation, sagittal angulation and cross-sectional area. All parameters are defined by the pedicle isthmus, i.e. the narrowest part of the pedicle perpendicular to the pedicle axis, and by the planes that define the symmetry of the vertebral body (Liljenqvist et al., 2002; Yu et al., 2014; Peters et al., 2015; Yu et al., 2015). 


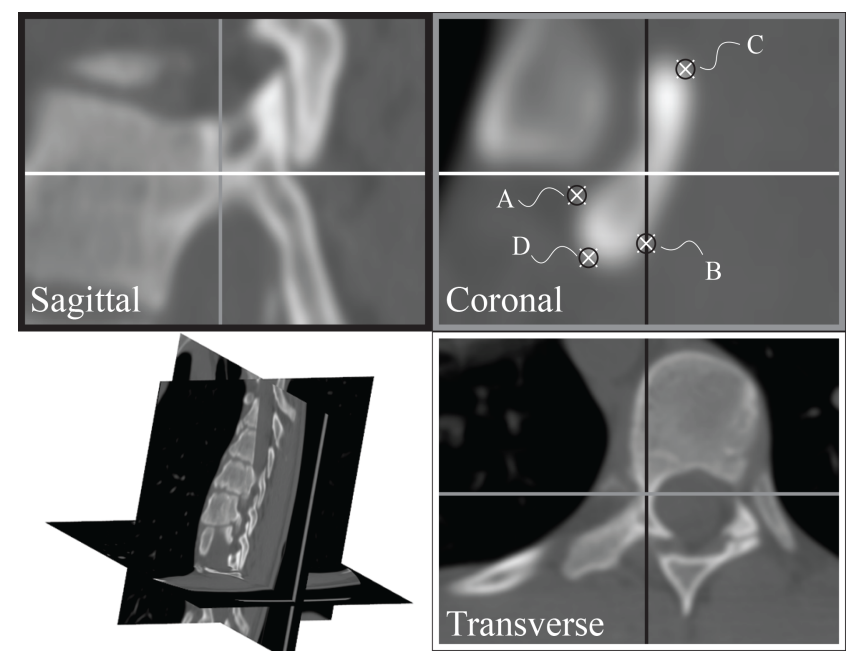

Fig. 2. Manual measurements of the pedicle width and height were performed by placing points $A, B, C$ and $D$ (Fig. 1) in a selected orthogonal (shown in this figure) and oblique multiplanar reconstruction.

\section{MANUAL MEASUREMENTS}

Manual measurements were performed for the pedicle width, height and chord length, which proved to be the most crucial pedicle morphometric parameters for selecting proper pedicle screw sizes in order to decrease the risk of pedicle and vertebral body wall breakthrough during their placement (Gstoettner et al., 2011). Measurements were performed by a single blinded observer (a medical imaging researcher with several years of experience in spine image analysis and manipulation), who used a dedicated inhouse computer program to manually place, with the computer mouse, specific points in selected orthogonal MPRs for each observed CT image, i.e. in sagittal, coronal and axial cross-sections of the image-based coordinate system. However, as measurements from orthogonal MPRs can be considerably influenced by the orientation of vertebrae in $3 \mathrm{D}$, the measurements were performed also in oblique MPRs, i.e. in sagittal, coronal and axial cross-sections of the pediclebased coordinate system, which was defined by positioning its axes so that they were aligned with and orthogonal to the pedicle longitudinal axis. The pedicle width and height were measured from both orthogonal and oblique MPRs, while the pedicle chord length was, in accordance with its definition, measured only from oblique MPRs. The in-house computer program guided the observer step-by-step through these measurements, and the final pedicle morphometric parameters were obtained by computing the distances between the placed points (Fig. 2).

\section{COMPUTERIZED MEASUREMENTS}

Computerized measurements were performed by an automated method that is based on parametric modeling of vertebral bodies and pedicles in 3D (Knez et al., 2016a;b), and can be applied to both normal and pathological cases of anatomy. Starting from parametric models in the form of elliptical cylinders, their 3D shape was, within a similarity-based optimization procedure, deformed to best represent the corresponding vertebral structures in each observed CT image (Fig. 3). Reference vertebral body and pedicle coordinate systems were then determined by finding the optimal transverse and sagittal planes of anatomical symmetry within the obtained 3D parametric models in their superior-to-inferior and left-to-right directions, respectively (Fig. 4). As a result, all pedicle morphometric parameters were determined completely in 3D, i.e. in the pedicle based coordinate system, and were obtained automatically by extracting the characteristic points and measuring the corresponding distances (pedicle width, height, length and chord length), angles (pedicle transverse and sagittal angulation) and area (pedicle cross-sectional area).

\section{STATISTICAL ANALYSIS}

To quantitatively compare manual and computerized measurements of each observed pedicle morphometric parameter, statistical analysis was applied to obtain the variability in terms of the mean absolute difference (MAD), corresponding standard deviation (SD) and intraclass correlation coefficient (ICC) using the one-way random effects model (McGraw and Wong, 1996). The repeated measures analysis of variance (ANOVA) with posthoc Tukey-Kramer analysis (Schlattmann and Dirnagl, 2010) was used to evaluate the statistical differences among measurements (level of significance: $\alpha=0.05$ ). All computations were performed in Matlab (version R2019b; MathWorks, Natick, MA, USA).

\section{RESULTS}

\section{PEDICLE DATABASE}

For the 26 observed patients, a total of 270 thoracic vertebrae between levels $\mathrm{T} 1$ and $\mathrm{T} 12$ were identified in the CT scans, forming a database of corresponding 540 (left and right) pedicles (Table 1 and Table 2). Because of the different field of view of the CT scans, the resulting number of pedicles differed for each vertebral level, and ranged from 20 (T1) to 52 (T8, T10, T11). 

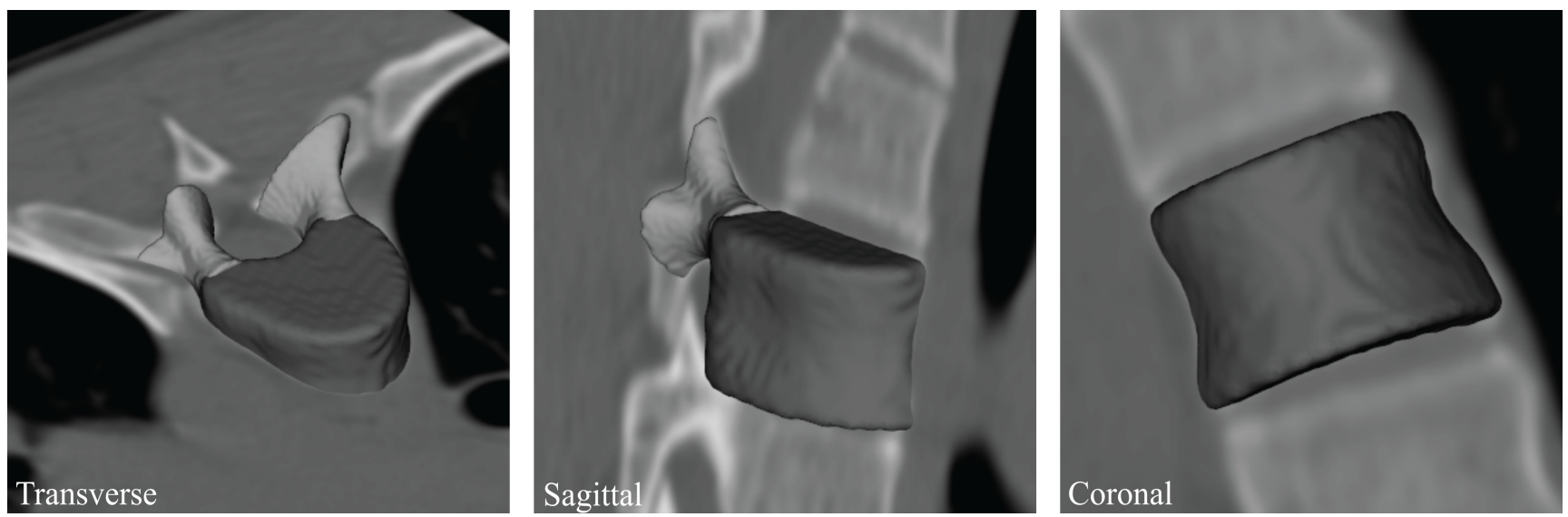

Fig. 3. An example of parametric modeling of the observed vertebral body and the corresponding pedicles in three dimensions, shown over oblique multiplanar computed tomography reconstructions..

\section{MANUAL MEASUREMENTS}

Pedicle morphometric parameters were first obtained by manually measuring the pedicle width and height from orthogonal MPRs, as well as the pedicle width, height and chord length from oblique MPRs, with the results reported in Table 1 . The range of the obtained measurements from orthogonal and oblique MPRs was, respectively, $3.1-15.1 \mathrm{~mm}$ and $2.5-$ $14.3 \mathrm{~mm}$ for the pedicle width, and $6.1-25.3 \mathrm{~mm}$ and $5.0-26.4 \mathrm{~mm}$ for the pedicle height, while the range of the pedicle chord length measured from oblique MPRs was $20.1-70.0 \mathrm{~mm}$. For all measurements, the smallest and largest values were, respectively, observed at levels T4 and T11 for the pedicle width, and at levels T1 and T11 for the pedicle height and chord length. The time required to obtain manual measurements for a single pedicle was estimated to around $1 \mathrm{~min}$ from orthogonal MPRs, and to around

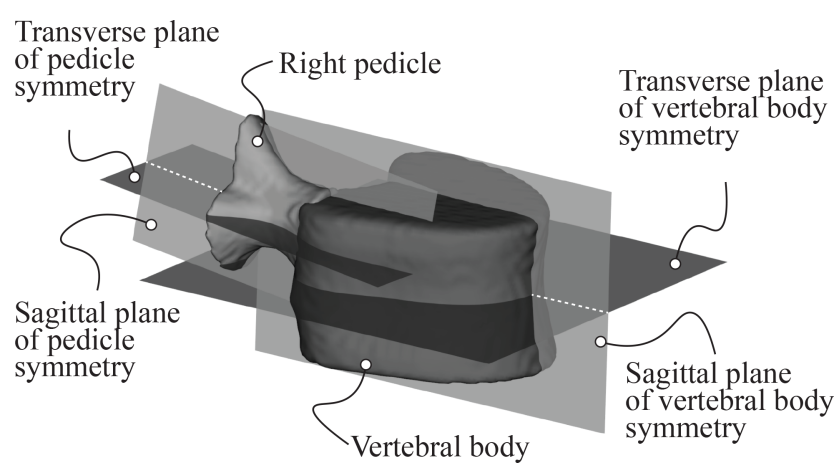

Fig. 4. Parametric models of a selected vertebral body and pedicle in three dimensions, and the corresponding transverse and sagittal planes of symmetry, obtained by the automated method for computerized measurements of pedicle morphometry.
2 min from oblique MPRs, which included also the manual determination of the pedicle-based coordinate system.

\section{COMPUTERIZED MEASUREMENTS}

Computerized measurements were based on parametric modeling of vertebral bodies and pedicles in $3 \mathrm{D}$ with an estimated accuracy (MAD $\pm \mathrm{SD}$ ) of, respectively, $\quad 0.39 \pm 0.31 \mathrm{~mm}$ and $0.31 \pm 0.25 \mathrm{~mm}$, evaluated as the distance between each model and the corresponding sets of manually placed anatomical points (Knez et al., 2016b). Pedicle morphometric parameters were then obtained in 3D by automatically measuring pedicle width, height, length, chord length, sagittal angulation, transverse angulation and crosssectional area, with the results reported in Table 1 and Table 2. The range of the obtained measurements was $2.2-15.1 \mathrm{~mm}$ for the pedicle width, $5.1-$ $24.9 \mathrm{~mm}$ for the pedicle height, $22.6-69.9 \mathrm{~mm}$ for the pedicle chord length, $10.5-37.6 \mathrm{~mm}$ for the pedicle length, $-12.9-35.8^{\circ}$ for the pedicle transverse angulation, $-7.6-21.7^{\circ}$ for the pedicle sagittal angulation, and $20.6-225.3 \mathrm{~mm}^{2}$ for the pedicle cross-sectional area. For all measurements, the smallest and largest values of pedicle width, height and chord length were observed at the same levels as for manual measurements. The time required to obtain computerized measurements for a single pedicle was estimated to around $6 \mathrm{~min}$, however, it was based on a non-optimal programming code without parallelization or graphical processing unit implementation. 
Table 1. Manual $(M)$ and computerized $(C)$ measurements (mean \pm standard deviation) of pedicle morphometric parameters, reported separately for each thoracic vertebral level $(\mathrm{Tl}-\mathrm{T12})$. For the pedicle width and height, manual measurements were obtained from both orthogonal (M-orth) and oblique (M-obl) multiplanar reconstructions (MPR), while for the pedicle chord length, they were obtained only from oblique (M-obl) MPRs. All computerized measurements were obtained directly in three dimensions. Note: The reported values are averaged across all patients and do not reflect eventual differences due to pathology or demographics.

\begin{tabular}{|c|c|c|c|c|c|c|c|c|c|}
\hline \multirow{2}{*}{$\begin{array}{l}\text { Vertebral } \\
\text { level }\end{array}$} & \multirow{2}{*}{$\begin{array}{c}\text { No. of } \\
\text { pedicles }\end{array}$} & \multicolumn{3}{|c|}{ Width (mm) } & \multicolumn{3}{|c|}{ Height (mm) } & \multicolumn{2}{|c|}{ Chord length (mm) } \\
\hline & & M-orth & M-obl & $\mathrm{C}$ & M-orth & M-obl & $\mathrm{C}$ & M-obl & $\mathrm{C}$ \\
\hline $\mathrm{T} 1$ & 20 & $3 \pm 1.6$ & $8.0 \pm 1.6$ & $7.9 \pm 1.4$ & $9.9 \pm 2.4$ & $9.6 \pm 2.4$ & $9.4 \pm 2.2$ & $30.9 \pm 2.8$ & $32.5 \pm 3.0$ \\
\hline $\mathrm{T} 2$ & 38 & & $6.9 \pm$ & $6.9=$ & .8 & 11.5 & 11.5 & 3.6 & $34.5 \pm 3.5$ \\
\hline $\mathrm{T} 3$ & 40 & & $5.7 \pm 1.2$ & $5.8 \pm$ & .0 & $12.3 \pm 1.5$ & $12.1=$ & & $35.0 \pm 4.7$ \\
\hline $\mathrm{T} 4$ & 44 & $5.5 \pm 1.2$ & $5.1 \pm 1.0$ & $5.4 \pm 1.0$ & $3.2 \pm 1.6$ & $12.3 \pm 1.6$ & $12.0 \pm 1.5$ & $33.3 \pm 4.6$ & $34.9 \pm 4.7$ \\
\hline $\mathrm{T} 5$ & 46 & $5.8 \pm 1.1$ & $5.3 \pm 1.0$ & $5.6 \pm 0.9$ & $13.0 \pm 2.0$ & $12.1 \pm 2.0$ & $11.7 \pm 1.9$ & $35.6 \pm 5.0$ & $37.5 \pm 4.6$ \\
\hline T6 & 48 & $6.0 \pm 1.1$ & $5.5 \pm 1.1$ & $5.7 \pm 1.2$ & $13.4 \pm 1.9$ & $12.4 \pm 2.0$ & $12.0 \pm$ & 38.2 & $39.5 \pm 5.2$ \\
\hline $\mathrm{T} 7$ & 48 & $6.3 \pm 1.3$ & $5.8 \pm 1.1$ & $5.9 \pm 1.2$ & $13.9 \pm 2.4$ & $12.4 \pm 2.0$ & $12.1 \pm$ & $40.2 \pm 6.1$ & $41.7 \pm 6.2$ \\
\hline $\mathrm{T} 8$ & 52 & $6.8 \pm 1.2$ & $6.2 \pm 1.1$ & $6.3 \pm 1.2$ & $14.2 \pm 2.8$ & $13.0 \pm 2.2$ & $12.5 \pm$ & $41.2 \pm 6.1$ & $42.7 \pm 6.3$ \\
\hline T9 & 50 & $7.2 \pm 1.4$ & $6.5 \pm 1.1$ & $6.6 \pm 1.1$ & $14.9 \pm 2.7$ & $14.1 \pm 2.6$ & $13.9 \pm 2.4$ & $43.8 \pm 7.7$ & $45.3 \pm 8.0$ \\
\hline $\mathrm{T} 10$ & 52 & $8.1 \pm 1.2$ & $7.4 \pm 1.2$ & $7.6 \pm 1.2$ & $16.7 \pm 3.1$ & $16.1 \pm 2.8$ & $15.8 \pm 2.8$ & $44.0 \pm 7.3$ & $45.5 \pm 7.1$ \\
\hline $\mathrm{T} 11$ & 52 & $9.0 \pm 1.7$ & $8.5 \pm 1.6$ & $8.7 \pm 1.5$ & $18.3 \pm 2.6$ & $17.6 \pm 2.6$ & $17.4 \pm 2.5$ & $44.0 \pm 8.8$ & $45.6 \pm 8.6$ \\
\hline $\mathrm{T} 12$ & 50 & $9.4 \pm 1.9$ & $8.7 \pm 1.8$ & $8.8 \pm 1.7$ & $17.7 \pm 2.4$ & $17.2 \pm 2.3$ & $16.9 \pm 2.4$ & $43.3 \pm 8.9$ & $44.8 \pm 8.4$ \\
\hline
\end{tabular}

\section{MANUAL VS. COMPUTERIZED MEASUREMENTS}

The distribution of measurements of pedicle width, height and chord length, obtained manually from orthogonal MPRs and oblique MPRs, and automatically by computerized measurements in 3D, is shown in Fig. 5. The analysis of normality with quantile-quantile (Q-Q) plots revealed that, with the exception of some outliers, the observed differences in measurements were approximately normally distributed. The ANOVA test with post-hoc analysis further revealed that manual measurements from orthogonal MPRs were significantly different in comparison to corresponding manual measurements from oblique MPRs, with the differences in terms of $\mathrm{MAD} \pm \mathrm{SD}$ (ICC; $p$-value) equal to $0.77 \pm 0.56 \mathrm{~mm}$ $\left(0.862 ; 2.7 \cdot 10^{-6}\right)$ for the pedicle width and $1.31 \pm 1.08 \mathrm{~mm}\left(0.860 ; 8.1 \cdot 10^{-5}\right)$ for the pedicle height. Manual measurements from orthogonal MPRs were also significantly different in comparison to corresponding computerized measurements in 3D, with the differences equal to $0.74 \pm 0.57 \mathrm{~mm}(0.863$; $\left.1.1 \cdot 10^{-3}\right)$ for the pedicle width and $1.45 \pm 1.10 \mathrm{~mm}$ $\left(0.840 ; 6.5 \cdot 10^{-8}\right)$ for the pedicle height. On the other hand, no statistically significant differences were observed between manual measurements from oblique MPRs and corresponding computerized measurements in $3 \mathrm{D}$, with the differences equal to
$0.44 \pm 0.35 \mathrm{~mm}(0.946 ; 0.37)$ for the pedicle width, $0.56 \pm 0.52 \mathrm{~mm}(0.970 ; 0.34)$ for the pedicle height and $1.72 \pm 1.29 \mathrm{~mm}(0.962 ; 0.12)$ for the chord length.

\section{DISCUSSION}

The insertion of pedicle screws into adjacent vertebral bodies through the corresponding pedicles for the purpose of treating various spinal deformities has become a widely accepted procedure in spine surgery, and a thorough knowledge of pedicle morphometry is essential to ensure a safe screw insertion (Liljenqvist et al., 2002; Kang et al., 2011; Seng et al., 2019). However, measurements of pedicle morphometry that were performed from orthogonal MPRs of CT or MR images (i.e. from sagittal, coronal and axial cross-sections of the image-based coordinate system) are not considered to be accurate, because they do not take into account the orientation of vertebrae that can be considerably large, especially in the presence of spinal deformities. Simpson et al. (2016) recently highlighted the discrepancy of pedicle morphometric parameters measured from orthogonal and oblique MPRs that was related to the orientation of pedicles. The authors concluded that measurements of the minimal pedicle diameter from orthogonal MPRs were overestimated in comparison to measurements 
Table 2. Additional computerized (C) measurements (mean \pm standard deviation) of pedicle morphometric parameters, reported separately for each thoracic vertebral level (T1-T12). All measurements were obtained directly in three dimensions. Note: The reported values are averaged across all patients and do not reflect eventual differences due to pathology or demographics.

\begin{tabular}{|c|c|c|c|c|c|}
\hline \multirow{2}{*}{$\begin{array}{c}\text { Vertebral } \\
\text { level }\end{array}$} & \multirow{2}{*}{$\begin{array}{c}\text { No. of } \\
\text { pedicles }\end{array}$} & \multirow{2}{*}{$\frac{\text { Length }(\mathrm{mm})}{\mathrm{C}}$} & \multirow{2}{*}{$\frac{\text { Sagittal angulation }\left(^{\circ}\right)}{\mathrm{C}}$} & \multirow{2}{*}{$\frac{\text { Transverse angulation }\left(^{\circ}\right)}{\mathrm{C}}$} & \multirow{2}{*}{$\frac{\text { Cross-sectional area }\left(\mathrm{mm}^{2}\right)}{\mathrm{C}}$} \\
\hline & & & & & \\
\hline $\mathrm{T} 1$ & 20 & $15.8 \pm 2.1$ & $9.5 \pm 6.6$ & $25.4 \pm 5.7$ & $62.8 \pm 20.0$ \\
\hline $\mathrm{T} 2$ & 38 & $16.7 \pm 2.1$ & $8.0 \pm 4.7$ & $16.4 \pm 5.8$ & $65.2 \pm 18.2$ \\
\hline $\mathrm{T} 3$ & 40 & $17.5 \pm 2.2$ & $7.4 \pm 3.4$ & $11.7 \pm 5.0$ & $59.3 \pm 15.4$ \\
\hline $\mathrm{T} 4$ & 44 & $17.7 \pm 1.6$ & $7.0 \pm 3.3$ & $8.0 \pm 6.0$ & $54.6 \pm 15.2$ \\
\hline $\mathrm{T} 5$ & 46 & $18.0 \pm 1.6$ & $8.0 \pm 2.8$ & $8.1 \pm 4.7$ & $54.1 \pm 15.1$ \\
\hline T6 & 48 & $18.1 \pm 1.9$ & $8.3 \pm 3.4$ & $7.7 \pm 5.0$ & $56.7 \pm 18.3$ \\
\hline $\mathrm{T} 7$ & 48 & $18.3 \pm 2.1$ & $8.4 \pm 3.7$ & $7.3 \pm 5.2$ & $60.1 \pm 18.6$ \\
\hline $\mathrm{T} 8$ & 52 & $18.6 \pm 2.4$ & $7.5 \pm 3.8$ & $6.3 \pm 5.5$ & $66.8 \pm 19.1$ \\
\hline T9 & 50 & $19.2 \pm 3.5$ & $5.4 \pm 3.4$ & $8.5 \pm 6.1$ & $77.9 \pm 23.4$ \\
\hline $\mathrm{T} 10$ & 52 & $18.9 \pm 3.1$ & $7.0 \pm 3.3$ & $7.9 \pm 6.5$ & $101.7 \pm 26.2$ \\
\hline $\mathrm{T} 11$ & 52 & $20.8 \pm 4.4$ & $6.5 \pm 3.3$ & $5.8 \pm 8.1$ & $124.1 \pm 33.0$ \\
\hline $\mathrm{T} 12$ & 50 & $23.1 \pm 3.9$ & $3.2 \pm 4.4$ & $1.1 \pm 7.3$ & $121.0 \pm 31.6$ \\
\hline
\end{tabular}

from oblique MPRs (i.e. from sagittal, coronal and axial cross-sections of the pedicle-based coordinate system), and that such overestimation increased with vertebral orientation.

In this paper, we performed manual and computerized measurements of pedicle morphometric parameters from CT images of the thoracic spine, and the corresponding quantitative comparison of the obtained measurements. Manual measurements were performed for those morphometric parameters that were feasible to be extracted from selected CT reconstruction planes: the pedicle width and height from orthogonal MPRs (i.e. in the image based coordinate system), and pedicle width, height and chord length from oblique MPRs (i.e. in the pediclebased coordinate system). Besides for the analysis of pedicle morphometry, these parameters are also most valuable for the determination of proper pedicle screw sizes. On the other hand, computerized measurements were always performed in 3D (i.e. in the pediclebased coordinate system) and allowed, along with the pedicle width, height and chord length, the extraction of additional morphometric parameters: the pedicle length, transverse angulation, sagittal angulation and cross-sectional area. The obtained manual and computerized measurements, reported in Table 1 and Table 2, are consistent with the existing studies on pedicle morphometry (Gstoettner et al., 2011; Zhuang et al., 2011; Peters et al., 2015; Kaur et al., 2016).

The most crucial parameter for the determination of the pedicle screw diameter is the pedicle width, which also provides the location of the pedicle isthmus (Simpson et al., 2016). For all measurements, the minimal pedicle width occurred at level T4 (Table 2), which is in agreement with the existing studies (Kang et al., 2011; Kaur et al., 2016). The comparison between manual measurements of the pedicle width and height from orthogonal MPRs, and those from oblique MPRs as well as computerized measurements in 3D revealed statistically significant differences. In fact, $\mathrm{MAD} \pm \mathrm{SD}$ of the pedicle width and height decreased, respectively, from $12 \pm 9 \%$ and $11 \pm 9 \%$ between manual measurements from orthogonal MPRs and computerized measurements in $3 \mathrm{D}$, to $7 \pm 5 \%$ and $4 \pm 4 \%$ between manual measurements from oblique MPRs and computerized measurements in 3D (Fig. 5). The results are therefore consistent with the findings of Simpson et al. (2016) and confirm the generally accepted opinion that measurements from orthogonal MPRs are not accurate because they do not take into account the orientation of vertebrae in 3D (Newton et al., 2015). On the other hand, the differences between manual measurements from oblique MPRs and computerized measurements in $3 \mathrm{D}$ were not found to be statistically significant, which additionally proves the correctness of the choice and design of the applied automated method. On average, these differences are approximately in the order of magnitude that corresponds to the mean pixel size for the pedicle width and mean slice thickness for the pedicle height (Table 1). For the 

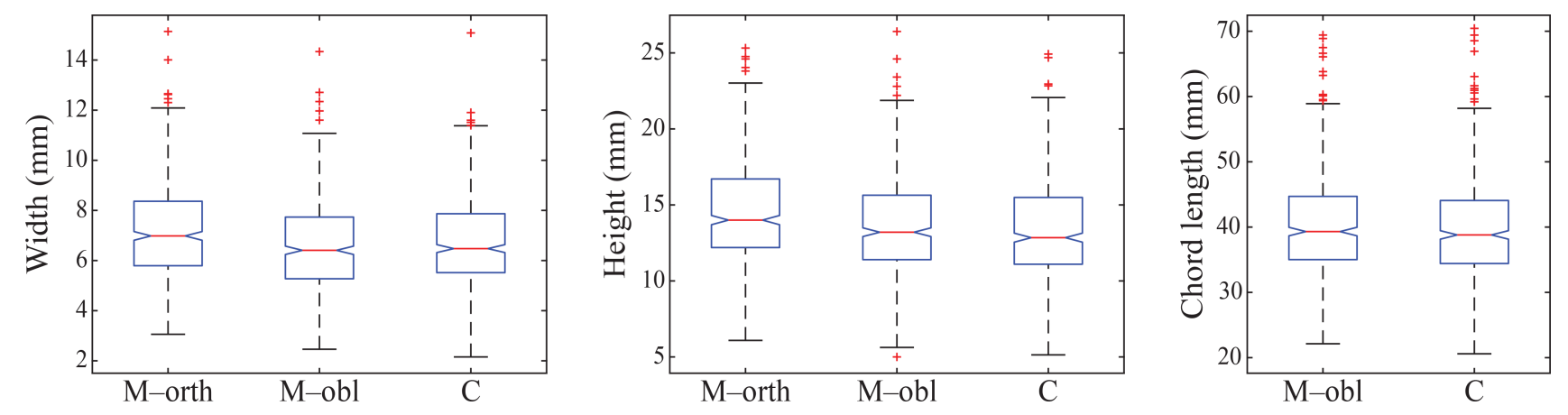

Fig. 5. Box-whiskers plots of the measurements of the pedicle width, height and chord length, obtained by manual measurements from orthogonal multiplanar reconstructions (MPRs) [M-orth], manual measurements from oblique MPRs [M-obl] and computerized measurements [C].

pedicle chord length, the comparison between manual and computerized measurements revealed that the differences were not statistically significant, however, computerized measurements in $3 \mathrm{D}$ resulted on average in $5 \pm 4 \%$ longer chord lengths(Fig. 5). Although previous studies reported that an increase/decrease of the pedicle screw length does not largely affect the pedicle screw fixation strength when compared to an increase/decrease in the screw diameter (Kang et al., 2011), the screw length is still a very important parameter because the choice for longer screws increases the risk of anterior vertebral body breakthrough that could potentially lead to internal organ injury.

In conclusion, we performed manual and computerized measurements of pedicle morphometric parameters completely in 3D from CT images of the thoracic spine, and provided a quantitative comparison and statistical analysis of the obtained results. The obtained differences between manual and computerized measurements indicate that manual measurements from orthogonal MPRs are, especially in the presence of spinal deformities, overestimated when compared to manual measurements from oblique MPRs or to computerized measurements in 3D. The main limitation of computerized measurements is that they may not be able to capture the whole natural biological variability of the pedicle shape as well as every pathological shape instance. On the other hand, the advantage of computerized measurements is that they allow the extraction of additional pedicle morphometric parameters, and can therefore provide a reliable support to spine surgeons in choosing proper screw sizes as well as insertion trajectories during preoperative planning of pedicle screw placement procedures. With a larger pedicle database, computerized measurements could also be used to determine pedicle morphometric parameters by focusing on a specific spinal pathology (e.g. scoliosis, spondylolisthesis) or demographic factor (e.g. gender, age, race) for the purpose of obtaining new knowledge about the indications and factors that can potentially alter the pedicle shape and geometry.

\section{ACKNOWLEDGEMENTS}

This work has been supported by the Slovenian Research Agency under projects P2-0232 and J2-7118.

\section{REFERENCES}

Brink R, Homans J, de Reuver S, van Stralen M, Schlösser T, Viergever M, Chu W, Ng B, Castelein $\mathrm{R}$, Cheng J (2020). A computed tomography-based spatial reference for pedicle screw placement in adolescent idiopathic scoliosis. Spine Deform 8:67-76.

Brink R, Schlösser T, Colo D, Vincken K, van Stralen M, Hui S, Chu W, Cheng J, Castelein R (2017). Asymmetry of the vertebral body and pedicles in the true transverse plane in adolescent idiopathic scoliosis: a CT-based study. Spine Deform 5:3745.

Chan C, Kwan M (2017). Safety of pedicle screws in adolescent idiopathic scoliosis surgery. Asian Spine J 11:998-1007.

Cordemans V, Kaminski L, Banse X, Francq B, Detrembleur C, Cartiaux O (2017). Pedicle screw insertion accuracy in terms of breach and reposition using a new intraoperative cone beam computed tomography imaging technique and evaluation of the factors associated with these parameters of accuracy: a series of 695 screws. Eur Spine J 26:2917-26.

Davis C, Grant C, Pearcy M, Askin G, Labrom R, Izatt M, Adam C, Little J (2017). Is 
there asymmetry between the concave and convex pedicles in adolescent idiopathic scoliosis? A CT investigation. Clin Orthop 475:884-93.

Fuchs M, Putzier M, Pumberger M, Hermann K, Diekhoff T (2016). Acute vertebral fracture after spinal fusion: a case report illustrating the added value of single-source dual-energy computed tomography to magnetic resonance imaging in a patient with spinal instrumentation. Skeletal Radiol 45:1303-6.

Gao B, Gao W, Chen C, Wang Q, Lin S, Xu C, Huang D, Su P (2017). What is the difference in morphologic features of the thoracic pedicle between patients with adolescent idiopathic scoliosis and healthy subjects? A CTbased case-control study. Clin Orthop Relat Res 475:2765-74.

Gstoettner M, Lechner R, Glodny B, Thaler M, Bach C (2011). Inter- and intraobserver reliability assessment of computed tomographic 3D measurement of pedicles in scoliosis and size matching with pedicle screws. Eur Spine J 20:1771-9.

Kang K, Song KS, Lee J, Yang J, Song I (2011). Comparison of radiographic and computed tomographic measurement of pedicle and vertebral body dimensions in Koreans: the ratio of pedicle transverse diameter to vertebral body transverse diameter. Eur Spine J 20:414-21.

Kaur K, Singh R, Prasath V, Magu S, Tanwar M (2016). Computed tomographic-based morphometric study of thoracic spine and its relevance to anaesthetic and spinal surgical procedures. J Clin Orthop Trauma 7:101-8.

Knez D, Likar B, Pernuš F, Vrtovec T (2016a). Automated determination of pedicle morphometry in the thoracic spine. In: 13th International Symposium on Biomedical Imaging - ISBI 2016. Prague, Czech Republic: IEEE.

Knez D, Likar B, Pernuš F, Vrtovec T (2016b). Computer-assisted screw size and insertion trajectory planning for pedicle screw placement surgery. IEEE Trans Med Imaging 35:1420-30.

Knez D, Nahle I, Vrtovec T, Parent S, Kadoury S (2019). Computer-assisted pedicle screw trajectory planning using CT-inferred bone density: a demonstration against surgical outcomes. Med Phys 46:3543-54.

Kong X, Tang L, Ye Q, Huang W, Li J (2017). Are computer numerical control (CNC)-manufactured patient-specific metal templates available for posterior thoracic pedicle screw insertion? Feasibility and accuracy evaluation. Eur Spine J 26:2927-33.
Kretzer R, Chaput C, Sciubba D, Garonzik I, Jallo G, McAfee P, Cunningham B, Tortolani P (2011). A computed tomography-based morphometric study of thoracic pedicle anatomy in a random United States trauma population. J Neurosurg Spine 14:235-43.

Kuraishi S, Takahashi J, Hirabayashi H, Hashidate H, Ogihara N, Mukaiyama K, Kato H (2013). Pedicle morphology using computed tomographybased navigation system in adolescent idiopathic scoliosis. J Spinal Disord Tech 26:22-8.

Lien SB, Liou NH, Wu SS (2007). Analysis of anatomic morphometry of the pedicles and the safe zone for through-pedicle procedures in the thoracic and lumbar spine. Eur Spine J 16:1215-22.

Liljenqvist U, Allkemper T, Hackenberg L, Link T, Steinbeck J, Halm H (2002). Analysis of vertebral morphology in idiopathic scoliosis with use of magnetic resonance imaging and multiplanar reconstruction. J Bone Joint Surg Am 84:359-68.

Ma J, Tang J, Wang D, Zhu Y, Sui T, Cao X (2016). Comparison of perpendicular to the coronal plane versus medial inclination for atlas pedicle screw insertion: an anatomic and radiological study in human cadavers. Int Orthop 40:141-7.

McGraw K, Wong S (1996). Forming inferences about some intraclass correlation coefficients. Psychol Methods 1:30-46.

Mohanty S, Pai Kanhangad M, Bhat S, Chawla S (2018). Morphometry of the lower thoracic and lumbar pedicles and its relevance in pedicle fixation. Musculoskelet Surg 102:299-305.

Morales-Avalos R, Leyva-Villegas J, SánchezMejorada G, Cárdenas-Serna M, Vílchez-Cavazos F, De León A, Elizondo-Riojas G, Martínez-García J, De La Garza-Castro O, Elizondo-Omaña R, Guzmán-López S (2014). Age- and gender-related variations in morphometric characteristics of thoracic spine pedicle: a study of 4,800 pedicles. Clin Anat 27:441-50.

Nault M, Mac-Thiong J, Roy-Beaudry M, Turgeon I, de Guise J, Labelle H, Parent S (2014). Threedimensional spinal morphology can differentiate between progressive and nonprogressive patients with adolescent idiopathic scoliosis at the initial presentation: a prospective study. Spine 39:E6016.

Newton P, Fujimori T, Doan J, Reighard F, Bastrom T, Misaghi A (2015). Defining the "threedimensional sagittal plane" in thoracic adolescent idiopathic scoliosis. J Bone Joint Surg Am 97:1694-701. 
Panjabi M, O’Holleran J, Crisco III J, Kothe R (1997). Complexity of the thoracic spine pedicle anatomy. Eur Spine J 6:19-24.

Parent S, Labelle H, Skalli W, de Guise J (2004). Thoracic pedicle morphometry in vertebrae from scoliotic spines. Spine 29:239-48.

Peters J, Chandrasekaran C, Robinson L, Servaes S, Campbell Jr R, Balasubramanian S (2015). Ageand gender-related changes in pediatric thoracic vertebral morphology. Spine J 15:1000-20.

Pishnamaz M, Lange H, Herren C, Na HS, Lichte P, Hildebrand F, Pape H, Kobbe P (2018). The quantity of bone cement influences the anchorage of augmented pedicle screws in the osteoporotic spine: a biomechanical human cadaveric study. Clin Biomech 52:14-9.

Pusceddu C, Fancellu A, Ballicu N, Fele R, Sotgia B, Melis L (2017). CT-guided percutaneous screw fixation plus cementoplasty in the treatment of painful bone metastases with fractures or a high risk of pathological fracture. Skeletal Radiol 46:539-45.

Sarwahi V, Sugarman E, Wollowick A, Amaral T, Lo Y, Thornhill B (2014). Prevalence, distribution, and surgical relevance of abnormal pedicles in spines with adolescent idiopathic scoliosis vs. no deformity. J Bone Joint Surg Am 96:e92.

Schlattmann P, Dirnagl U (2010). Statistics in experimental cerebrovascular research: comparison of more than two groups with a continuous outcome variable. J Cereb Blood Flow Metab 30:1558-63.

Seng W, Chou S, Siddiqui S, Oh J (2019). Pedicle screw designs in spinal surgery: is there a difference? A biomechanical study on primary and revision pull-out strength. Spine 44:E144-9.

Simpson V, Clair B, Ordway N, Albanese S, Lavelle W (2016). Are traditional radiographic methods accurate predictors of pedicle morphology? Spine 41:1740-6.

Takeshita K, Allardyce T, Chikuda H, Shoda N, Seichi A, Ono T, Nakamura K (2009). Diameter, length, and direction of pedicle screws for scoliotic spine: analysis by multiplanar reconstruction of computed tomography. Spine 34:798-803.

Vaccaro A, Rizzolo S, Allardyce T, Ramsey M, Salvo J, Balderston R, Cotler J (1995). Placement of pedicle screws in the thoracic spine. Part I: morphometric analysis of the thoracic vertebrae. $\mathrm{J}$ Bone Joint Surg Am 77:1193-9.

Vrtovec T, Janssen M, Pernuš F, Castelein R, Viergever M (2012). Analysis of pelvic incidence from 3dimensional images of a normal population. Spine 37:E479-85.

Wang X, Boyer L, Naveaux F, Schwend R, Aubin CE (2016). How does differential rod contouring contribute to 3-dimensional correction and affect the bone-screw forces in adolescent idiopathic scoliosis instrumentation? Clin Biomech 39:11521.

Wojnar L, Gądek-Moszczak A, Pietraszek J (2019). On the role of histomorphometric (stereological) microstructure parameters in the prediction of vertebrae compression strength. Image Anal Stereol 38:63-73.

Yang M, Zhao Q, Hao D, Chang Z, Liu S, Yin X (2019). Comparison of clinical results between novel percutaneous pedicle screw and traditional open pedicle screw fixation for thoracolumbar fractures without neurological deficit. Int Orthop 43:1749-54.

Yu C, Bajwa N, Toy J, Ahn U, Ahn N (2014). Pedicle morphometry of upper thoracic vertebrae: an anatomic study of 503 cadaveric specimens. Spine 39:E1201-9.

Yu C, Yuh R, Bajwa N, Toy J, Ahn U, NU A (2015). Lower thoracic pedicle morphometry: male, taller, and heavier specimens have bigger pedicles. Spine 40:E323-31.

Zhuang Z, Chen Y, Han H, Cai S, Wang X, Qi W, Kong K (2011). Thoracic pedicle morphometry in different body height population: a threedimensional study using reformatted computed tomography. Spine 26:E1547-54. 